\title{
Effect of Some Analytical Organic Indicators on the Corrosion of Nickel in Carbonate Solution
}

\author{
M. Abdallah, ${ }^{1, *}$ S.M. Abdel-Waneess, ${ }^{2}$ R. Assi ${ }^{1}$ \\ ${ }^{1}$ Chemistry Department, Faculty of Science, Banha University, Banha, Egypt \\ Chemistry Department, Faculty of Science, Zagazig University, Zagazig, Egypt
}

Received 26 May 2008; accepted 17 February 2009

\begin{abstract}
The effect of some analytical organic indicators, e.g. methyl red, methyl orange and methyl violet, on the corrosion of nickel electrode in $0.1 \mathrm{M} \mathrm{K}_{2} \mathrm{CO}_{3}$ was studied using galvanostatic and potentiodynamic anodic polarization techniques. The percentage inhibition efficiency was found to increase with increasing concentration of these compounds. The inhibitive action of these compounds is due to their adsorption on the nickel surface, making a barrier to mass and charge transfer, following Freundlich isotherm. The inhibition efficiency decreases in the order: methyl red $>$ methyl orange $>$ methyl violet. It was found that the addition of the chloride, bromide, iodide and thiosulfate ions accelerates the pitting corrosion of nickel in $0.1 \mathrm{M} \mathrm{K}_{2} \mathrm{CO}_{3}$ solutions by shifting the pitting potential to more negative direction. The addition of these analytical organic compounds protects the nickel against pitting corrosion in bromide containing solution.
\end{abstract}

Keywords: methyl red, methyl orange, methyl violet, nickel, corrosion inhibitors, pitting corrosion.

\section{Introduction}

Nickel and nickel alloys are important materials for the design vessels in different processes in industry. Nickel electrode is also used in different energyproducing cell in which aqueous or non aqueous solutions are used as electrolytes. Nickel and its alloys exhibit excellent corrosion resistance in aqueous aggressive environments, which is attributed to the ability of nickel to form a stable passive film on its surface [1]. Among alternative corrosion inhibitors, organic compounds containing polar functions with nitrogen, oxygen,

\footnotetext{
* Corresponding author. E-mail address: metwally552@ hotmail.com
} 
sulfur atoms in conjugated system have been reported as effective inhibitors of nickel corrosion [2-6]. Their inhibitive action is connected with several factors, including the structure and charge distribution of the molecule, the number and types of adsorption sites and the nature of interaction between the molecule and the metal surface [7].

A recent contribution involves the study of organic indicators, whose molecules possess certain desirable characteristics as potential inhibitors in metal corrodent systems $[8,9]$.

The aim of this work is to study the effect of some organic analytical indicators, e.g. methyl red, methyl orange and methyl violet, on the corrosion of nickel in $0.1 \mathrm{M} \mathrm{K}_{2} \mathrm{CO}_{3}$ solution using galvanostatic polarization measurements. Moreover, the ability of these compounds to provide a protection against pitting corrosion was studied using potentiodynamic anodic polarization technique.

\section{Experimental}

Nickel electrode with purity $99.99 \%$ provided by Merck was used in this study. For galvanostatic experiments, a cylindrical rod was embedded in araldite leaving an exposed bottom area of $0.196 \mathrm{~cm}^{2}$, and used as working electrode. This working electrode was polished with different grades of emery papers, degreased with acetone and rinsed with distilled water, before its immersion in the test solution. Galvanostatic and potentiodynamic anodic polarization techniques were carried out using a PS remote potentiostat with PS6 software for calculation of corrosion parameters. A three compartment cell with a saturated calomel reference electrode (SCE) and a platinum foil auxiliary electrode was used. The inhibition efficiency (IE) and surface coverage $(\theta)$ were calculated using the following equations:

$$
\begin{gathered}
\% \mathrm{IE}=[(\mathrm{I}-\mathrm{Ii}) / \mathrm{I}] \times 100 \\
\theta=\left[\left(\mathrm{I}-\mathrm{I}_{\mathrm{i}}\right) / \mathrm{I}\right]
\end{gathered}
$$

where I and Ii are the corrosion rates in free and inhibited alkaline solutions, respectively. All chemicals used for preparing the test solution were of analytical grade and the experiments were carried out at room temperature, $25 \pm 1{ }^{\circ} \mathrm{C}$.

The chemical structures of these organic additives are:

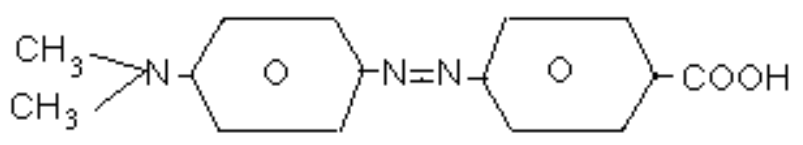

Compound 1: methyl red.

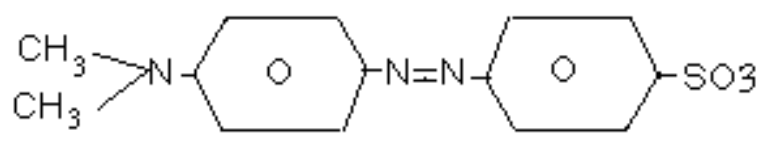

Compound 2: methyl orange. 


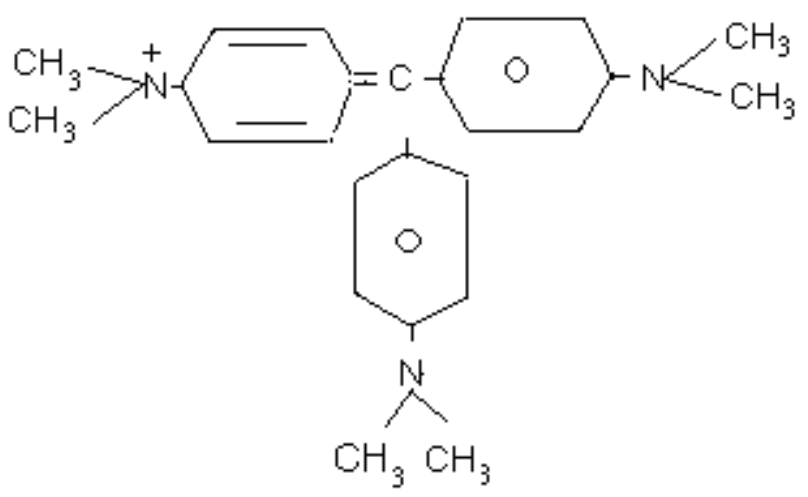

Compound 3: methyl violet or crystal violet, or gentiana violet.

\section{Results and discussion}

\section{Galvanostatic polarization studies}

The effect of addition of some organic additives (methyl red, methyl orange and methyl violet) on the anodic and cathodic polarization curves for nickel in $0.1 \mathrm{M}$ $\mathrm{K}_{2} \mathrm{CO}_{3}$ solution at $25{ }^{\circ} \mathrm{C}$ was studied. The effect of increased concentration of methyl red is represented, as an example, in Fig. 1. However, similar curves were obtained for other two compounds (not shown). From Fig. 1, one can observe at first that there is a transition region in which the potential increases (anodic polarization) or decreases (cathodic polarization) slowly with current density, followed by a rapid linear build up of potential with current density (Tafel region).

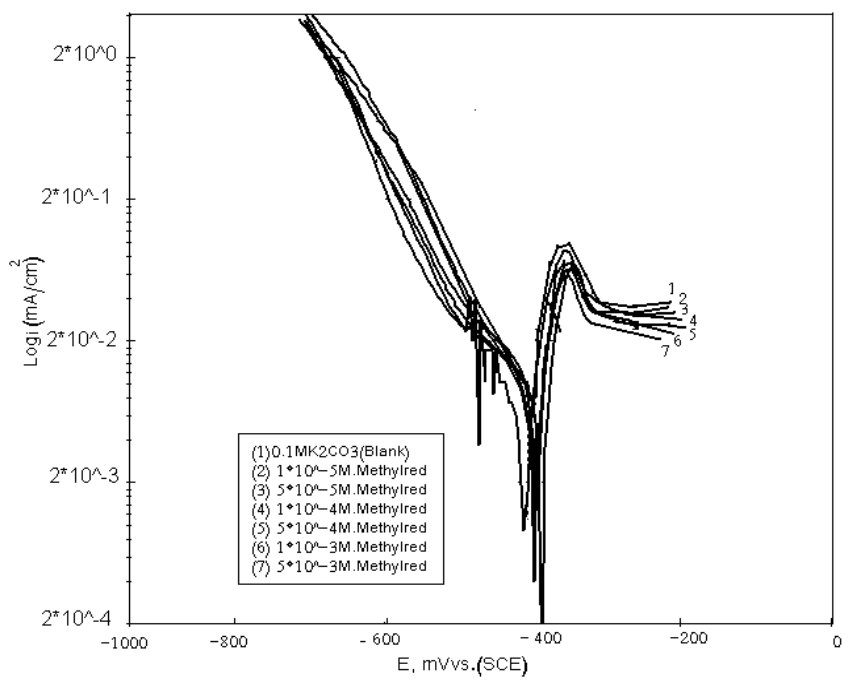

Figure 1. Galvanostatic polarization curves for nickel in $0.1 \mathrm{M} \mathrm{K}_{2} \mathrm{CO}_{3}$ in absence and presence of different concentrations of methyl red.

Table 1 shows the effect of additives concentration on the corrosion kinetic parameters such as corrosion potential (Ecorr), corrosion current density (Icorr), cathodic and anodic Tafel slopes ( $\beta \mathrm{c}$ and $\beta \mathrm{a})$, surface coverage $(\theta)$ and inhibition efficiency (\%IE), obtained from galvanostatic polarization measurements at 25 
${ }^{\circ} \mathrm{C}$. The corrosion current density (Icorr) and corrosion potential (Ecorr) were determined by the interaction of the extrapolating anodic and cathodic Tafel lines, \%IE was calculated from eq. (1) and $\beta c$ and $\beta$ a are the slope of the cathodic and anodic Tafel lines, respectively.

Table 1. Electrochemical parameters for nickel electrode in free $\mathrm{K}_{2} \mathrm{CO}_{3}$ and inhibited $\mathrm{K}_{2} \mathrm{CO}_{3}$ solution at $25^{\circ} \mathrm{C}$.

\begin{tabular}{lcccccc}
\hline Concentration & $\begin{array}{c}\text {-Ecorr / } \\
\mathrm{mV}(\mathrm{SCE})\end{array}$ & $\begin{array}{c}\text { Icorr } \times 10^{4} / \\
\mathrm{mA} \cdot \mathrm{cm}^{-2}\end{array}$ & $\begin{array}{c}\beta \mathrm{c} / \\
\mathrm{mV} \cdot \mathrm{dec}^{-1}\end{array}$ & $\begin{array}{c}\beta \mathrm{a} / \\
\mathrm{mV} \cdot \mathrm{dec}^{-1}\end{array}$ & $\theta$ & $\% \mathrm{IE}$ \\
\hline $0.1 \mathrm{M} \mathrm{K}_{2} \mathrm{CO}_{3}+$ methyl red & & & & & & \\
0 & 445 & 2533 & 235.57 & 70.23 & & \\
$1 \times 10^{-5}$ & 434 & 2162 & 219.86 & 69.10 & 0.150 & 14.60 \\
$5 \times 10^{-5}$ & 430 & 2059 & 209.95 & 67.89 & 0.190 & 18.70 \\
$1 \times 10^{-4}$ & 428 & 2027 & 208.20 & 66.54 & 0.200 & 20.00 \\
$5 \times 10^{-4}$ & 423 & 2017 & 186.15 & 64.40 & 0.200 & 20.30 \\
$1 \times 10^{-3}$ & 422 & 1325 & 181.24 & 58.54 & 0.477 & 47.70 \\
$5 \times 10^{-3}$ & 421 & 1243 & 176.08 & 54.56 & 0.509 & 50.90 \\
\hline $0.1 \mathrm{M} \mathrm{K}_{2} \mathrm{CO}_{3}+$ methyl orange & & & & & \\
0 & 445 & 2533 & 235.58 & 70.23 & & \\
$1 \times 10^{-5}$ & 440 & 2316 & 222.95 & 69.82 & 0.086 & 8.50 \\
$5 \times 10^{-5}$ & 437 & 2292 & 220.01 & 68.42 & 0.095 & 9.50 \\
$1 \times 10^{-4}$ & 432 & 2120 & 196.46 & 66.66 & 0.163 & 16.30 \\
$5 \times 10^{-4}$ & 430 & 1917 & 185.30 & 61.24 & 0.243 & 24.30 \\
$1 \times 10^{-3}$ & 428 & 1910 & 164.74 & 59.26 & 0.246 & 24.60 \\
$5 \times 10^{-3}$ & 426 & 1393 & 143.90 & 58.26 & 0.450 & 45.00 \\
\hline $0.1 \mathrm{M} \mathrm{K}_{2} \mathrm{CO}_{3}+$ methyl violet & & & & & \\
0 & 445 & 2533 & 235.58 & 70.23 & & \\
$1 \times 10^{-5}$ & 439 & 2475 & 227.77 & 66.57 & 0.023 & 2.30 \\
$5 \times 10^{-5}$ & 435 & 2377 & 219.82 & 62.66 & 0.062 & 6.16 \\
$1 \times 10^{-4}$ & 431 & 2158 & 206.43 & 60.82 & 0.148 & 14.80 \\
$5 \times 10^{-4}$ & 427 & 2103 & 192.51 & 59.36 & 0.169 & 16.90 \\
$1 \times 10^{-3}$ & 424 & 2075 & 183.88 & 58.97 & 0.181 & 18.10 \\
$5 \times 10^{-3}$ & 423 & 1884 & 175.63 & 55.19 & 0.256 & 25.00 \\
\hline
\end{tabular}

The inspection of Table 1 reveals that the increasing concentration of the additives leads to the following:

(a) The Tafel lines are shifted to more positive and negative potential for anodic and cathodic processes, respectively, relative to the blank curve. This means that these compounds influence both cathodic and anodic processes. However, the data suggested that these compounds act mainly as mixed type inhibitors, but the cathode is more polarized when an external current was applied $\beta \mathrm{c}>\beta \mathrm{a}$.

(b) Ecorr changed slightly and the values of Icorr decrease indicating the inhibiting effect of these compounds.

(c) The inhibition efficiencies of the three tested compounds by the galvanostatic polarization method decrease in the following order

methyl red $>$ methyl orange $>$ methyl violet 


\section{Adsorption isotherm}

The experimental data for the tested inhibitors have been applied to different adsorption isotherm equations. The best correlation fits the Freundlich adsorption isotherm [10] which is given as:

$$
\theta=\mathrm{K} \mathrm{C}^{\mathrm{n}}
$$

or alternatively, by

$$
\log \theta=\log \mathrm{k}+\mathrm{n} \log \mathrm{C}
$$

where $\mathrm{k}$ and $\mathrm{C}$ represent the equilibrium constant of adsorption process and additive concentration, respectively.

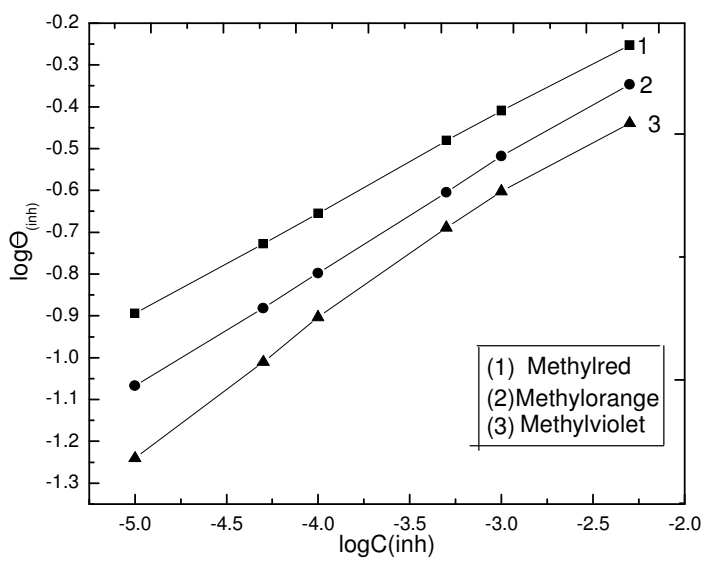

Figure 2. Freundlish adsorption isotherm. 1) methyl red; 2) methyl orange; 3) methyl violet.

Fig. 2 represents the Freundlish adsorption plots for the compound studied (log $\theta$ vs. $\log$ C).The data gave straight lines with intercept of $\log \mathrm{k}$. The calculated values for the equilibrium constant of adsorption were found to be $39.8 \times 10^{-2}$, $63.09 \times 10^{-2}$ and $89.1 \times 10^{-2}$ for methyl red, methyl orange and methyl violet, respectively.

The equilibrium constant value $\mathrm{k}$ is related to the standard free energy of adsorption $\Delta \mathrm{G}_{\text {ads }}^{\circ}$ by the following equation [11]:

$$
\mathrm{K}=1 / 55.5 \exp \left[-\Delta \mathrm{G}^{\circ} \text { ads } / \mathrm{RT}\right]
$$

where 55.5 is the concentration of water in solution in $\mathrm{mol} / \mathrm{L}, \mathrm{R}$ is the universal gas constant and $\mathrm{T}$ is the absolute temperature. The values of $\Delta \mathrm{G}^{\circ}$ ads for methyl red, methyl orange, and methyl violet amount to $-3.3,-3.8$ and $-4.13 \mathrm{kJmol}^{-1}$, respectively. The negative values of $\Delta \mathrm{G}^{\circ}$ ads indicate the spontaneous adsorption of the inhibitor on the metal surface and they are usually characteristic of strong interaction with the metal surface.

\section{Pitting corrosion studies}

The effect of some aggressive ions, e.g. $\mathrm{Cl}^{-}, \mathrm{Br}^{-}, \mathrm{I}^{-}$, andS $\mathrm{O}_{2} \mathrm{O}_{3}{ }^{2-}$, in the pitting corrosion of nickel in $0.1 \mathrm{M} \mathrm{K}_{2} \mathrm{CO}_{3}$ solution was examined by potentiodynamic anodic polarization measurements. Fig. 3 shows the potentiodynamic anodic 
polarization curves of nickel electrode in $0.1 \mathrm{M} \mathrm{K}_{2} \mathrm{CO}_{3}$ using different concentrations of $\mathrm{KBr}$ at scan rate $1 \mathrm{mVs}^{-1}$. Similar curves (not shown) were obtained for other aggressive ions: $\mathrm{Cl}^{-}, \mathrm{I}^{-}$and $\mathrm{S}_{2} \mathrm{O}_{3}{ }^{2-}$.

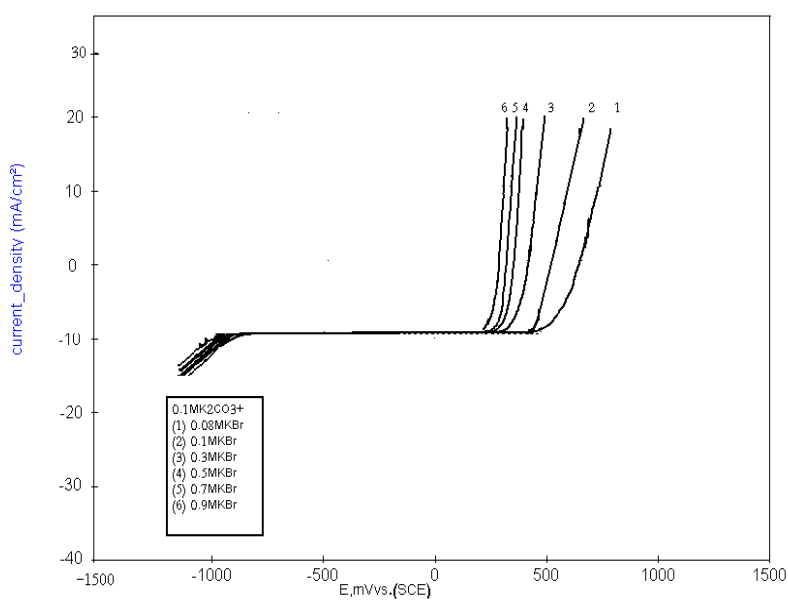

Figure 3. Potentiodynamic anodic polarization curves of nickel in $0.1 \mathrm{M} \mathrm{K}_{2} \mathrm{CO}_{3}$ in absence and presence of different concentrations of $\mathrm{KBr}$ (aggressive).

An inspection of curves in Fig. 3 reveals that an addition of $\mathrm{Br}^{-}$ions does not change the shape of polarization curves recorded in halide free solution. In the concentration range of these studied aggressive ions, the metal does not exhibit an active-passive transition. However, on increasing the concentration of these ions, there is a sudden and marked increase of current density at a definite potential, indicating the passivity breakdown and initiation of pitting corrosion [12]. The potential at which the sudden rise takes place is defined as the pitting potential $\left(\mathrm{E}_{\text {pitt }}\right)$. The higher concentration of $\mathrm{Cl}^{-}$ion, the higher is the shift of pitting potential toward the active direction. The breakdown of passivity could be attributed to the adsorption of chloride ions on the passive film/solution interface $[13,14]$. Thus, when the electrostatic field reaches a certain value, the adsorbed anions begin to penetrate into the passive film and the pitting corrosion is initiated.

Fig. 4 represents the relationship between pitting potential, Epitt, and logarithm of the molar concentration of the aggressive ions. From this figure it is clear that the tendency of nickel electrode to pitting corrosion decreases in the following order: $\mathrm{Cl}^{-}>\mathrm{Br}^{-}>\mathrm{I}^{-}>\mathrm{S}_{2} \mathrm{O}_{3}{ }^{2}$. The shape of curves obtained indicates that:

i) at low concentration of aggressive ions the pitting potential shift slightly in negative direction because the aggressive ions are not sufficient to destroy completely the passivity film on the metal surface;

ii) at relatively higher concentrations of aggressive ions, Epitt varies with concentration of aggressive ions according to a straight line relationship in the form $[15,16]$

$$
\text { Epitt }=a_{1}-b_{1} \log C a g g
$$


where $a_{1}$ and $b_{1}$ are constants which depend on both the nature and the type of aggressive anion and of the electrode. This behavior is attributed to the destruction of the passive film formed on the metal surface and the pits formed continuously propagate and can not undergo repassivation [17].

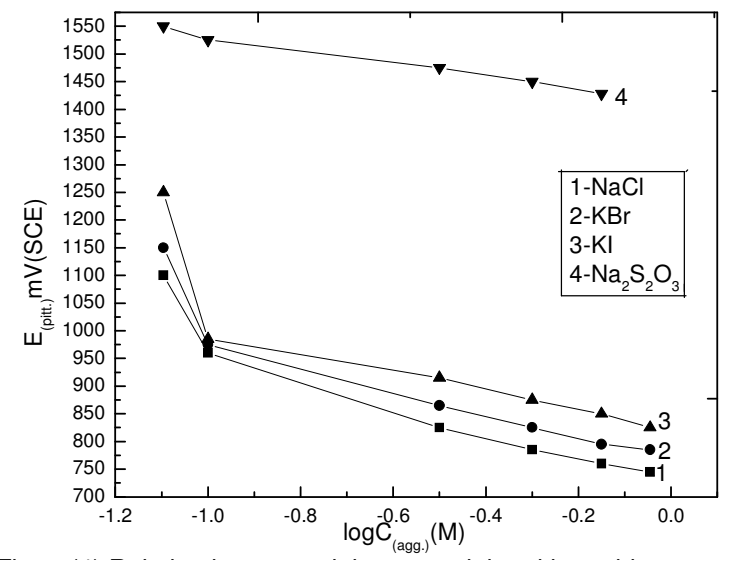

Figure 4. Relation between pitting potential and logarithm of the molar concentration of aggressive ions for nickel in $0.1 \mathrm{M} \mathrm{K}_{2} \mathrm{CO}_{3}$.

\section{Inhibition of pitting corrosion}

The effect of increasing addition of the studied inhibitors on the potentiodynamic anodic polarization curves in $0.1 \mathrm{M} \mathrm{K}_{2} \mathrm{CO}_{3}+0.7 \mathrm{M} \mathrm{KBr}$ was studied. Similar curves (not shown) to those of Fig. 3 were obtained in the presence of these compounds. In their presence, the pitting potential was shifted toward more positive direction. This indicates the inhibitive effect of these compounds for pitting corrosion.

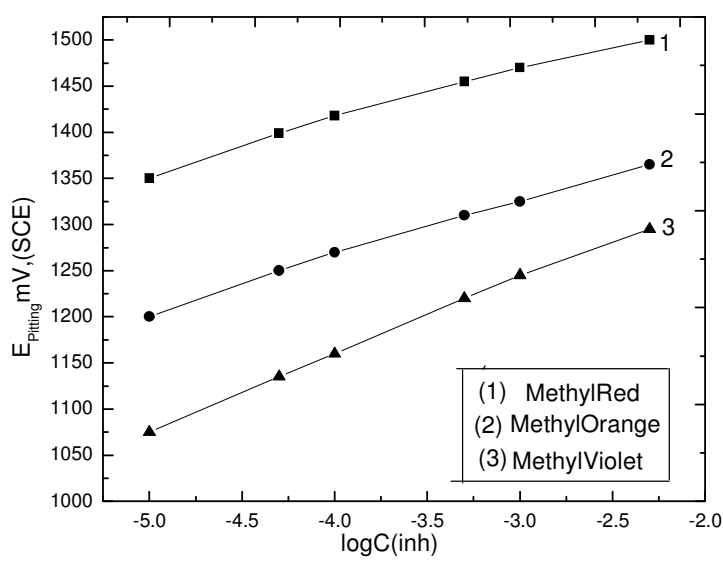

Figure 5. Relation between pitting potential and logarithm of the molar concentration of organic additive in $0.1 \mathrm{M} \mathrm{K}_{2} \mathrm{CO}_{3}+0.7 \mathrm{M} \mathrm{KBr}$. 
Fig. 5 represents the relationship between Epitt and $\log$ Cinh. From the curves of this figure, the following conclusions could be drawn:

(i) an increase of inhibitor concentration results in a positive shift of Epitt in accordance with the following equation:

$$
\text { Epitt }=\mathrm{a}_{2}+\mathrm{b}_{2} \log \text { Cinh }
$$

where $a_{2}$ and $b_{2}$ are constants which depend on both the type of additive and the nature of the electrode;

ii) inhibition afforded by these compounds decreases in the following order: methyl red $>$ methyl orange $>$ methyl violet

\section{The inhibition mechanism}

The corrosion inhibition of these organic indicator compounds towards the corrosion of nickel in $0.1 \mathrm{M} \mathrm{K}_{2} \mathrm{CO}_{3}$ solution may be attributed to the adsorption of these compounds at the metal/solution interface, where the adsorbed molecules mechanically screen the coated part of the metal surface from the action of the corrodent. The extent of the adsorption of the inhibitor depends on the nature of the metal, the mode of adsorption of the inhibitors and the surface conditions.

The results indicated that the (\% IE) of the organic compounds is more or less dependent on the nature of the constituents. The orders of (\%IE) and the positive shift of pitting corrosion potential decreased in the following order: methyl red > methyl orange $>$ methyl violet. This sequence may be attributed to: methyl red and methyl orange have an active center for adsorption azo group $(\mathrm{N}=\mathrm{N})$. This leads to that methyl red and methyl orange have higher (\%IE) than methyl violet, but the methyl red has higher (\%IE) than methyl orange. This may be attributed to the higher basicity of methyl red. The sulphonic group $\left(\mathrm{SO}_{3}\right)^{2-}$ in methyl orange is more electron withdrawing group than the carboxylic group $(\mathrm{COO})^{-}$ present in methyl red.

\section{Conclusions}

i) Methyl red, methyl orange, and methyl violet act as inhibitors for corrosion of nickel in $0.1 \mathrm{M} \mathrm{K}_{2} \mathrm{CO}_{3}$ solution at $25^{\circ} \mathrm{C}$.

ii) The inhibition efficiency increases with the increase in the concentration of these inhibitors.

iii) The inhibition is due to the adsorption of the inhibitor molecule on nickel surface.

iv) The adsorption of these compounds on the nickel surface follows Freundlich adsorption isotherm.

v) Methyl red, methyl orange, and methyl violet provide protection against pitting corrosion of nickel in presence of bromide ions. 


\section{References}

1. D.D.N. Singh, M.K. Banerjee, CorrosionNACE 42 (1986) 156.

2. M. Abdallah, A.Y. EL-Etre, Port. Electrochim. Acta 21 (2003) 315.

3. A.A. Aksut, S. Bilgic, Corros. Sci. 33 (1992) 379.

4. A. Frignani, C. Monticelli, G.Trabanelli, Br. Corros. J. 33 (1998) 71.

5. A.Y. EL-Etre, M. Abdallah, Z.E. EL-Tantawy, Corros. Sci. 47 (2005) 385.

6. F. Lallemand, D. Auguste, C. Amato, L. Hevesi, J. Delhalle, Z. Mekhalif, Electrochim. Acta 52 (2007) 4341.

7. E.E. Ebenso, Mater. Chem. Phys. 71 (2002) 62.

8. E.E. Oguzie, Materials Letters 59 (2005) 1076.

9. E.E. Oguzie, B.N. Okolue, E.E. Ebenso, G.N. Onuoha, A.I. Onuchukwu, Mater. Chem. Phys. 87 (2-3) (2004) 394.

10. B.B. Damaskin, O.A. Petrii, V.V. Batra Kov, "Adsorption of Organic Compounds on Electrodes", Plenum Press, New York (1971).

11. M. Kliskic, J. Rosevic, Gndic, J. Appl. Electrochem. 27 (1997) 947.

12. Ja.M. Kolotyrkin, Corrosion 19 (1963) 261t.

13. M. Abdallah, Port. Electrochim. Acta 22 (2004) 161.

14. M. Abdallah, Annali di Chimica 83 (1993) 423.

15. Z.A. Foroulis, M.J. Thubriker, Werkstoff. U. Korros 26 (1975) 250.

16. S.M. Abd El-Haleem, S.S. Abd El Rheem, A.M. Azzam, Werkstoff. $U$. Korros 27 (1976) 630.

17. S.M. Abd El-Haleem, Br.Corros. J. 14 (1979) 177. 